Antitrust Bulletin, vol. XLIII (1998), no.2, pp. 429-444.

\title{
THE INEFFICIENCY OF THE ECPR YET AGAIN: A REPLY TO LARSON
}

\author{
by \\ Nicholas Economides and Lawrence J. White* \\ February 1996
}

\begin{abstract}
We extend the results of our article, "Access and Interconnection Pricing? How Efficient Is the "Efficient Component Pricing Rule?," Antitrust Bulletin (1995). In the presence of a monopolized essential input, we show that application of the Efficient Component Pricing Rule ("ECPR") in pricing this input to downstream competitors perpetuates monopoly distortions and high prices of final goods services. We show these results for various demand conditions, including conditions that are accepted to hold in the telecommunications sector. We also respond to various criticisms raised by A. Larson in "The Efficiency of the Efficient-Component-Pricing Rule: A Comment," Antitrust Bulletin, (this issue) (1998).
\end{abstract}

Stern School of Business, New York University, NY 10012-1126.

Tel. (212) 998-0864, (212) 998-0860, FAX (212) 995-4218, e-mail: neconomi@ stern.nyu.edu, http://edgar.stern.nyu.edu/networks/, lwhite@stern.nyu.edu. 


\title{
THE INEFFICIENCY OF THE ECPR YET AGAIN: A REPLY TO LARSON
}

\author{
by Nicholas Economides and Lawrence J. White*
}

\section{Introduction}

In our original article ${ }^{1}$ our primary purpose was to develop a relatively simple theoretical point: that the strict application of the "efficient component pricing rule" (ECPR) could lead regulators and antitrust adjudicators to reach decisions that would inefficiently protect incumbent bottleneck monopolies against challenges by entrants or rivals in the production and sale of complementary components. We used the example of a local-exchange telephone monopolist that also competes with a rival in the provision of long-distance service (which requires access to the local exchange) primarily as a way of illustrating our point in a way that most readers would find intuitively easy to grasp. We believe that our theoretical point has widespread applicability, beyond our telephone example, in many regulated industries, in unregulated industries, and in antitrust adjudications.

Alexander Larson's Comment ${ }^{2}$ attempts primarily to make one point: that our analysis does not apply empirically to the telecommunications industry.

We disagree, for the reasons that are explained below. But even if Larson were correct with respect to our model's applicability to some telecommunications markets, its applicability to other telecommunications markets and other industries is unaffected. Further, Larson does not

\footnotetext{
* Stern School of Business, New York University

${ }^{1}$ Nicholas Economides \& Lawrence J. White, Access and Interconnection Pricing? How Efficient Is the "Efficient Component Pricing Rule"?, 40 ANTITRUST BULL. 557 (1995).

${ }^{2}$ Alexander C. Larson, The Efficiency of the Efficient-Component-Pricing Rule: A Comment, 41 ANTITRUST BULL. (this issue) (1996).
} 
really challenge our central public policy point: that a general policy of preventing technologically less efficient challengers from competing with incumbents (especially incumbents with market power) would be soundly rejected by virtually anyone who is interested in sensible public policy. However, this undesirable inhibition of competition is a direct consequence of the $E C P R$, as our model demonstrates.

The remainder of this Reply will proceed as follows: Section II will again lay out the simple intuition of the ECPR. Section III will reprise our model and its insights. Section IV will summarize Larson's critique. Section V will provide our response. Section VI will address some global issues with respect to our differences with Larson. And Section VII will offer a brief conclusion.

\section{The Intuition of the ECPR}

The ECPR is designed to provide a pricing solution to problems involving an incumbent monopolist that controls a crucial or bottleneck facility and that also produces a complementary component in competition with an actual or potential rival. The pricing question is, "What should the rival pay to the monopolist for access to the latter's bottleneck facility?" The ECPR's answer is, "The rival should pay a fee that reimburses the monopolist for its opportunity costs; these opportunity costs include any incremental costs occasioned by the rival's use of the bottleneck facility itself and also any net revenue that the monopolist loses in the sale of the complementary component (or the integrated good or service, consisting of the complementary 
component and the bottleneck service) as a consequence of the rival's sale. ${ }^{3}$ A logical consequence of this answer -- which is trumpeted proudly by the advocates of the ECPR -- is that only rivals that are at least as cost-efficient as the monopolist in the production of the complementary component will be able to compete in the sale of the integrated good or service; inefficient rivals will be excluded by the application of the ECPR. ${ }^{4}$

\section{Our Model}

The ECPR result that was just stated has a seductive appeal. After all, how can one object to policies that prevent inefficiency?

Suppose, however, that the monopolist is earning monopoly rents on the sale of the integrated service -- either because the integrated service is unregulated (even though the bottleneck service might be regulated) or because the integrated service is subject to regulation that has somehow permitted these monopoly rents. Then the presence of even a less-efficient rival could cause prices to decrease sufficiently so that the increase in consumer surplus (i.e., the reduction in the size of the "deadweight loss triangle" originally created by the monopolist's high prices) would be larger than the cost inefficiency created by the rival's production of some of the complementary component, yielding a net gain in social efficiency. ${ }^{5}$ The ability of the

${ }^{3}$ The citations for the development of this argument can be found in our original article, supra note 1 .

${ }^{4}$ A numerical example demonstrating this result can be found in our original article, supra note 1 at 562-563, and in virtually all of the pro-ECPR literature cited there.

5 It is important to note that in our calculation of this net improvement we counted the transformation of the monopolist's profits into consumer surplus as a pure transfer. It is surely the case that in most political contexts, the transformation of monopoly profits into consumer surplus would be counted as part of the net social gain, which would strengthen our results. 
"inefficient" rival's presence to generate this net social gain would depend on the price-elasticity of demand for the integrated service, the size of the initial monopoly mark-up, ${ }^{6}$ the size of the post-entry mark-up (if any), the degree of inefficiency of the rival, and the post-entry market share captured by the rival.

To illustrate the possibility that even a significantly disadvantaged rival could yield a net social gain when challenging an incumbent monopolist, we used two standard oligopoly frameworks -- Bertrand and Cournot -- to model the post-entry duopoly behavior of the incumbent and the rival, a range of demand elasticities, and (for Bertrand) a range of market shares for the rival. ${ }^{7}$

\section{Larson's Critique}

Larson's criticism of our article consists primarily of a set of claims that our analysis "bears little relation to real regulated markets in the telecommunications industry." ${ }^{8} \mathrm{He}$ argues (a) that the demand elasticities and market shares that we used in our illustration "are extremely unrealistic for markets in telecommunications;"9 (b) that regulators prevent the local exchange carriers (LECs) from setting prices at full profit-maximizing monopoly levels; ${ }^{10}$ (c) that the limit

\footnotetext{
${ }^{6}$ In a model of a simple unregulated monopoly, of course, the monopoly mark-up would be determined by the elasticity of demand.

${ }^{7}$ For the Cournot model, the rival's market share is determined endogenously and it depends on its cost disadvantage.

${ }^{8}$ Larson supra note 2 , at ...

${ }^{9} I d$. at ...

${ }^{10} I d$. at ...
} 
pricing strategy of the incumbent in our Bertrand model is "rather implausible and unrealistic;"11 (d) that the assumption of Bertrand competition for the complementary component "is unrealistic for the telecommunications industry;"12 (e) that the ECPR is necessary so that the incumbent LECs can recover the fixed costs of their local exchange networks and/or maintain the crosssubsidy of basic exchange services that has been forced upon them by regulators; ${ }^{13}$ (f) that, in instances where the entrant is more efficient than the incumbent, our analysis ignores the fact that access fees are regulated and ignores the possibility of dynamic adjustment of the ECPR fee ${ }^{14}$ and (g) that we advocate "an ad hoc marginal cost pricing rule for access" to the bottleneck facility." 15

\section{V. $\quad \underline{\text { Response }}$}

We will deal with Larson's claims in serial fashion.

\section{A. Demand elasticities and market shares}

${ }^{11}$ Id. at ....

${ }^{12} I d$. at ...

${ }^{13} I d$. at ... We find Larson's claim that "basic local exchange service is normally below cost" (id. at ....) to be most curious -- and potentially revealing. First, the phrase "below cost" is ambiguous at best. More important, in the following paragraph Larson claims that "basic local exchange service and exchange access service..... are the downstream [sic] services which are increasingly subject to competition." But we normally do not expect to observe profit-seeking firms to enter lines of business where prices truly are "below cost" -- unless such entry then gives them the ability to earn rents in related markets.

${ }^{14}$ Id. at .....

${ }^{15}$ Id. at.... 
Because our model began with an unregulated monopolist, it was necessary to use demand elasticities that were greater than 1.0; otherwise, the monopolist would increase the price until it reached the elastic part of the demand, or charge an infinitely high price if the demand is everywhere inelastic. We concede that the commonly discussed price elasticities for long distance are in the 0.4-0.75 range and that the demand elasticity for basic local exchange service is substantially smaller. Still, long distance and basic service are not the only places where the LECs face actual or potential competition. There are many complementary services -- such as cellular telephone, paging services, pay telephones, customer-supplied PBX systems, remotebased answering services -- which require access to the local exchange network and for which the price elasticities of demand could well be greater than 1.0. In these cases, our model would apply.

Even if the demand is inelastic at the point of operation of the incumbent (say because the incumbent is constrained by regulation), the basic point of our model is valid: entry of moderately inefficient rivals will typically increase social welfare if the ECPR is not applied, while such entry will be foreclosed if the ECPR is applied. Referring to Figure 1 , let $\mathrm{P}_{\mathrm{o}}, \mathrm{Q}_{0}$, and $\mathrm{MC}=\mathrm{c}$ be the

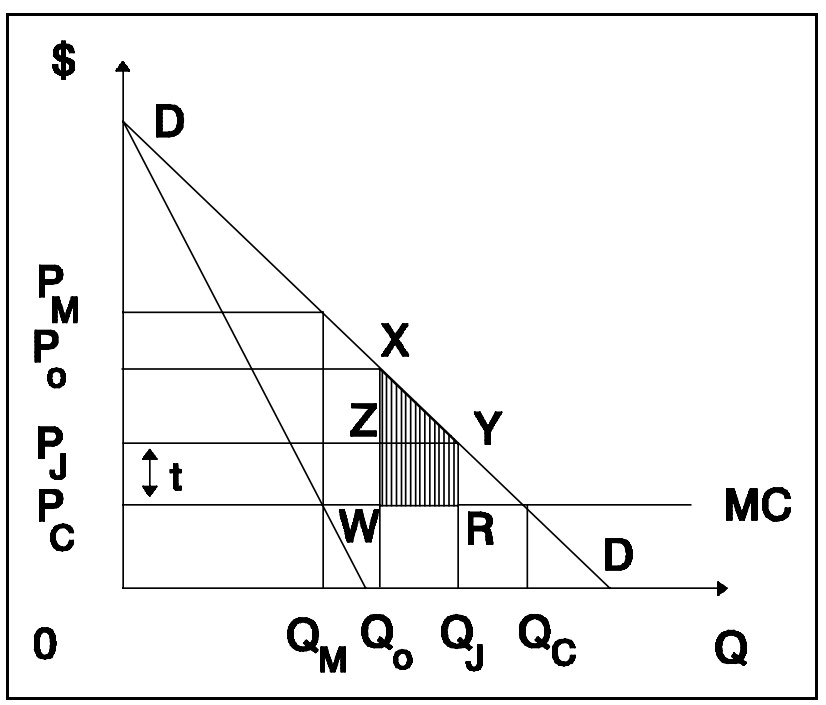

Figure 1: Dead Weight Loss and Production Inefficiency with Original Price $P_{0}<P_{M}$ incumbent's original price, quantity, and marginal cost respectively, and suppose, as in Larson's example, that the demand is inelastic at 
the point of operation. Since this choice by the monopolist cannot be the result of unconstrained profit maximization, the formulas in the appendix of our original article do not apply. ${ }^{16}$ However, the thrust of our main argument still goes through. If the ECPR is not applied, the entry of a firm with a marginal cost inefficiency equal to $\mathrm{t}, 0 \leq \mathrm{t} \leq \mathrm{P}_{\mathrm{o}}-\mathrm{c}$, will reduce price to $\mathrm{P}_{\mathrm{J}}=\mathrm{c}+\mathrm{t}$ and increase quantity to $\mathrm{Q}_{\mathrm{J}}$ under Bertrand competition. Entry results in a change in welfare of $\left(\mathrm{Q}_{\mathrm{J}}-\mathrm{Q}_{\mathrm{o}}\right)\left(\mathrm{P}_{\mathrm{o}}-\mathrm{P}_{\mathrm{J}}\right) / 2+\mathrm{t}\left(\mathrm{Q}_{\mathrm{J}}-\mathrm{Q}_{\mathrm{o}}\right)-\theta t \mathrm{Q}_{\mathrm{J}}$, where $\theta$ is the percentage of the market covered by the entrant. Given $\mathrm{P}_{0}, e$, and $\theta$, there exists a $\mathrm{t}^{*}>0$, such that entry by firms with smaller cost inefficiency than $\mathrm{t}^{*}$ creates welfare gains. The exact formula for $\mathrm{t}^{*}$ is established in the appendix. Of course, application of the ECPR would exclude all inefficient entrants.

Let us take Larson's example of intra-LATA long-distance service, and let us accept Larson's estimate of the price-elasticity of demand for this service at 0.56 . Though the prices of intra-LATA long-distance service are regulated by state regulators, it is well known that the LECs' profit margins on this service are quite high. One category of evidence that is consistent with this observation is the fierce political lobbying that the LECs have conducted to exclude the inter-LATA long-distance carriers (e.g., AT\&T, MCI, Sprint) from these markets entirely or to hobble them by not allowing them to offer pre-subscription ("one-plus dialing") service. Let us assume that the LECs' mark-up is $50 \%$ over marginal costs and that post-entry competition is Bertrand. Applying the same logic that underlay our original analysis as described above, we can show that entrant market shares of $0 \%$ (i.e., the mere threat of entry causes the LEC to

\footnotetext{
${ }^{16}$ In this context, Larson erred when he used our appendix formulas for situations involving inelastic demand ( $i d$., note 2 at ....). Instead, he too should have estimated the pre-entry markup for the incumbent regulated monopolist and then calculated the gains and losses from entry as we do below.
} 
practice limit pricing), 50\%, and 100\% (the same three benchmarks that we used in our original article) would imply maximum cost disadvantages (for a rival whose entry can still be socially beneficial) of $50 \%, 8 \%$, and $4 \%$, respectively. Application of the ECPR would foreclose these rivals.

Finally, we chose the benchmark market shares for the entrant of $0 \%, 50 \%$, and $100 \%$ simply to show the full range (and midpoint) of potential market shares for the entrant.

We can similarly prove that, under Cournot competition, moderately inefficient entrant(s) will also typically increase social welfare if the ECPR is not applied, while such entry will be foreclosed if the ECPR is applied. ${ }^{17}$

\section{B. The alleged effectiveness of regulators}

Not all of the complementary services provided by the LECs are subject to binding regulation that necessarily prevents "full profit-maximizing" prices. Some services are simply not regulated. Others are sometimes rolled into bundles, with the bundles subject to various forms of price-cap regulation. In this form of regulation, though the composite price index for the bundle may be constrained, the prices of individual services within the bundle may well be unconstrained.

17 The equilibrium price under Cournot competition, even for equally efficient firms, depends on the number of competitors, and decreases to marginal cost as the number of competitors increases. Thus, given an initial pre-entry price $P_{0}$, there exists a number $n>1$, so that entry of n-1 Cournot competitors (equally efficient with the original firm) leads to a lower equilibrium price, $\mathrm{P}(\mathrm{n})<\mathrm{P}_{0}$, and results in a welfare increase. Further, given an initial pre-entry price $\mathrm{P}_{0}$, there exist numbers $\mathrm{m} \geq \mathrm{n}$ and maximum degrees of inefficiencies $\mathrm{t}^{*}(\mathrm{~m})$, so that entry of $\mathrm{m}-1$ Cournot competitors with marginal cost $\mathrm{c}+\mathrm{t}, \mathrm{t}<\mathrm{t}^{*}(\mathrm{~m})$ result in a lower equilibrium price, $\mathrm{P}(\mathrm{m}, \mathrm{t})<\mathrm{P}_{\mathrm{o}}$, and a welfare increase. 
More importantly, as we showed in the previous section, the logic of our analysis does not require that the incumbent is charging "full profit-maximizing" prices for complementary components, but only that there are some positive rents embodied in the incumbent's prices. We doubt that Larson would deny this reality, even in the telecommunications industry.

\section{Informational Requirements of Limit Pricing}

We chose the Bertrand model, and the limit pricing that is implied by the model, for part of our analysis because it is a standard duopoly model and it is tractable. It provides useful insights into an important set of possible outcomes. Further, it is in the context of Bertrand competition for undifferentiated products that ECPR can be proved to be efficient under extremely restrictive assumptions. ${ }^{18}$ Though incumbent LECs might not have the precise information about their rival's costs that is assumed by the model, we expect that they could form fairly good approximations through engineering analyses (in house or by consultants) and/or through trial-and-error pricing experiments. Accordingly, we believe that something close to the limit pricing of our model would be a reasonable possibility for the LECs. After all, as Larson would surely agree, models are meant to provide insights and useful approximations to reality, not to mimic it exactly.

\section{The Assumed Form of Competition}

We explained in the previous section our reasons for using the Bertrand model. Larson objects that "in telecommunications incumbent firms have extremely limited downward pricing

18 Economides \& White supra note 1. 
flexibility." 19 Again, however, not all LECs' prices are subject to regulation, and even those that are subject to price-cap regulation are likely to have considerable within-bundle flexibility. Moreover, we did not limit our analysis to the Bertrand model with no product differentiation. We also used the Cournot model reaching similar conclusions. ${ }^{20}$ Since it is well understood that the Cournot model can mimic Bertrand competition with horizontally differentiated products, we also covered the possibility of product differentiation.

\section{E. The alleged necessity of the ECPR for covering fixed costs and/or forced cross-subsidy}

In our primary model we assumed the presence of constant marginal costs in the provision of the bottleneck services as a simplifying device that allowed us to focus on the points that we considered to be important. We later discussed the case of increasing returns and made the point -- which has been made by virtually all authors in the field -- that in this case Ramsey pricing would be the correct policy strategy and that only by extreme coincidence would the ECPR coincide with the Ramsey pricing rule.

Of course, if one wishes to define and constrain the problem so narrowly -- e.g., that regulators have constrained all other prices and that these other prices are absolutely immutable - then one can always force the answer that any rents that the incumbent monopolist earns in the sale of the complementary component are absolutely necessary to cover the costs that the

${ }^{19} I d$., note 2 at ...

20 Larson erred in stating that we claim that "... under 'softer' competition, any market presence by a less efficient rival will be socially deleterious" id. ... In fact we stated exactly the opposite: "even with Cournot duopoly, nontrivial cost inefficiencies by the rival are consistent with a net social gain" Economides \& White supra note 1 at 569 also quoted in Larson supra at ... 
regulators have caused to be left uncovered elsewhere and thus that the ECPR is unambiguously the correct (and only!) answer to the problem. We do not find such cramped analysis to be interesting. Again, the Ramsey rule is the right (second best) rule. In the presense of fixed costs, the ECPR is nth best $(n>2)$.

F. Our alleged neglect of regulation of access fees when the entrant is more efficient than the incumbent

As our original article argued, if the entrant is more efficient in producing the complementary component than is the incumbent, the latter's profit-maximizing strategy is usually to cede production to the entrant and charge an access fee that will allow the continued capture of all of the rents. A regulated access fee that is equal to the ECPR would cause prices to be maintained at an artificially high price that reflected the incumbent's previous market power. We did not assume an absence of regulation.

Further, yes, in this instance an iterative ("dynamic") regulatory process might cause access fees to be lowered subsequently. But it is important to note that this iterative process would have no beneficial effect when the entrant is less efficient (our primary case), because the application of the ECPR would prevent the entry that might otherwise lead to Larson's iterative process. A priori, there is no way to know if the entrant is going to be more efficient or less efficient than the incumbent. Relying on an iterative regulatory process to somehow make things better would be hit-or-miss at best.

G. Our alleged advocacy of "an ad hoc marginal cost pricing rule for access" 
Nowhere in our original article did we advocate a specific pricing rule for access, other than endorsing the generalized Ramsey approach. Again, in our specific model we assumed for simplicity that constant marginal costs characterized the bottleneck facility and hence that the entrant's access charge was a marginal cost payment. But, surely, simplifying a model so as to emphasize a particular point ought not by itself to be characterized as "advocacy." Again, we later recognize and endorse the necessity for a generalized Ramsey approach if fixed costs need to be recovered.

\section{VI. $\quad$ Some Global Issues}

Toward the end of his Comment Larson reproduces and states as "well known" our list of the necessary conditions for the optimality of the ECPR: (1) the monopolist's price for the complementary service has been based on a marginal-cost pricing rule; (2) the monopolist's and rival producer's components are perfect substitutes; (3) the production technology of the component experiences constant returns to scale; (4) the rival producer has no market power; and (5) the monopolist's marginal cost of production of the component can be accurately observed. ${ }^{21}$

Larson then claims, "In real telecommunications markets these assumptions are not likely to be violated very often." 22 We find his arguments to support this claim wholly unconvincing. As we argued above, many of the LECs' complementary services are not priced at marginal cost. Further, to use the intra-LATA long-distance example favored by Larson, not only do the LECs

${ }^{21}$ Economides \& White, supra note 1 at 559-560; Larson, supra note 2 at .... Our original list, as was indicated in the article, was drawn from Jean-Jacques Laffont \& Jean Tirole, Access Pricing and Competition, 38 EURO. ECON. REV. 1673 (1994).

${ }^{22}$ Larson, supra note 2 at .... 
earn rents on those services but their rivals -- when they have been permitted to enter at all -have frequently not been able to offer "one plus" service; the necessity for customers to dial extra digits surely makes these rivals' intra-LATA long-distance offerings imperfect (and inferior) substitutes for the LECs' "one plus" service. Similarly, pay telephones with varying features, customer-supplied PBXs, and answering services with varying features offer imperfect substitutes for the LECs' offerings. Finally, hundreds of millions of dollars have been expended on regulatory filings and hearings and on court challenges precisely because the marginal (and other) costs of the LECs' regulated services are not transparent. Indeed, in addition to the encouragement for future technological improvements, a major justification for price-cap regulation has been these difficulties in determining the LECs' costs.

Our differences with Larson are perhaps best summarized by the following: Early in his Comment Larson mentions "an interesting 'Catch 22' of access pricing and regulation: if the downstream prices .... are at efficient levels, the very issue of .... the ECPR is largely moot.... However, if downstream prices are too high .... the correct pricing of access is an important issue." ${ }^{23}$ Let us rephrase and expand on this paradox: If the conditions under which the ECPR would be efficient are present, its application is redundant; if they are absent, its application would be a mistake (as compared with a more optimal Ramsey rule).

Despite this "Catch 22," Larson apparently believes that the ECPR should enjoy a strong presumption of applicability, especially in the telecommunications industry. We beg to differ.

\section{Conclusion}

\footnotetext{
${ }^{23} I d$., note 2 at ....
} 
The appropriate pricing of access to a monopolist's bottleneck facility poses interesting theoretical questions and will increasingly be important in the policy realm, especially in light of the open-access provisions of the Telecommunications Act of 1996, the growing pressures toward open access in natural gas and electricity distribution, ${ }^{24}$ and a growing antitrust interest in "network effects" in many industries. ${ }^{25}$

In our original article we offered a simple model that, we believe, raises serious questions about the applicability of the ECPR in many real-world situations. Larson's Comment offered some criticisms of our analysis, especially in its applicability to the telecommunications industry, and the tone and content of the Comment indicate that Larson believes that the application of the ECPR would not be so bad after all, especially in telecommunications.

For the reasons stated in this Reply, we believe that our original arguments concerning the flaws in the ECPR have not been seriously undercut by Larson, even for applications in telecommunications. Accordingly, we feel comfortable repeating the admonition with which we closed our original article: "In sum, in real-world settings policy makers should be wary of blind devotion to the ECPR. It has dangers as well as benefits, and the real-world settings may well be ones in which the dangers outweigh the benefits." 26

\footnotetext{
${ }^{24}$ See, for example, Richard J. Pierce, Jr., The State of the Transition to Competitive Markets in Natural Gas and Electricity, 15 ENERGY L. J. 32 (1994).

${ }^{25}$ See, for example, Nicholas Economides \& Lawrence J. White, Networks and Compatibility: Implications for Antitrust, 38 EURO. ECON. REV. 651 (1994); and Nicholas Economides, The Economics of Networks, 14 INT. J. INDUS. ORG. (1996, forthcoming).

${ }^{26}$ Economides \& White, supra note 1 at 575.
} 


\section{Appendix}

This appendix establishes conditions under which entry by an inefficient rival results in social gain, even when the pre-entry incumbent's price is below the monopoly price, and possibly at an inelastic part of the demand. Given the pre-entry incumbent's price $P_{0}$, quantity $Q_{0}$, and market elasticity $e$ at the point of operation, entry of a firm with marginal cost disadvantage $\mathrm{t}, 0 \leq \mathrm{t} \leq \mathrm{P}_{\mathrm{o}}-\mathrm{c}$, results in a welfare gain equal to

$$
\Delta \mathrm{W}=(\Delta \mathrm{P})(\Delta \mathrm{Q}) / 2+\mathrm{t}(\Delta \mathrm{Q})-\theta \mathrm{tQ}_{\mathrm{J}}
$$

where $\Delta \mathrm{P}=\mathrm{P}_{\mathrm{o}}-\mathrm{P}_{\mathrm{J}}$ and $\Delta \mathrm{Q}=\mathrm{Q}_{\mathrm{J}}-\mathrm{Q}_{\mathrm{o}} ; \theta$ is the post-entry market share of the entrant. Below we find the range of $t,\left[0, t^{*}\right)$ such that entry results in a welfare gain, $\Delta \mathrm{W}>0$. Since $\mathrm{P}_{\mathrm{J}}=\mathrm{c}$ $+\mathrm{t}, \Delta \mathrm{P}=\mathrm{P}_{\mathrm{o}}-\mathrm{c}-\mathrm{t}$. Using the definition of elasticity, we have

$$
\Delta \mathrm{Q} \sim \mathrm{eQ}_{\mathrm{o}}(\Delta \mathrm{P}) / \mathrm{P}_{\mathrm{o}} .
$$

Substituting for $\Delta \mathrm{Q}$ and $\Delta \mathrm{P}$, the welfare change can be approximated as

$$
\begin{gathered}
\Delta \mathrm{W} \sim \mathrm{eQ}_{\mathrm{o}}(\Delta \mathrm{P})^{2} / \mathrm{P}_{\mathrm{o}} / 2+\operatorname{te} \mathrm{Q}_{\mathrm{o}}(\Delta \mathrm{P}) / \mathrm{P}_{\mathrm{o}}-\mathrm{t} \theta \mathrm{Q}_{\mathrm{o}}\left(\mathrm{P}_{\mathrm{o}}+\mathrm{e}(\Delta \mathrm{P})\right) / \mathrm{P}_{\mathrm{o}} \\
=\left[\mathrm{Q}_{\mathrm{o}} / \mathrm{P}_{\mathrm{o}}\right]\left[\mathrm{e}(\Delta \mathrm{P})^{2} / 2+\operatorname{te}(\Delta \mathrm{P})-\mathrm{t} \theta\left(\mathrm{P}_{\mathrm{o}}+\mathrm{e}(\Delta \mathrm{P})\right)\right] \\
\equiv\left[\mathrm{Q}_{\mathrm{o}} / \mathrm{P}_{\mathrm{o}}\right] \mathrm{f}(\mathrm{t})
\end{gathered}
$$

where

$$
\begin{aligned}
f(t)= & e\left(P_{o}-c-t\right)^{2} / 2+t e\left(P_{o}-c-t\right)-t \theta\left(P_{o}+e\left(P_{o}-c-t\right)\right) \\
& =e(\theta-1 / 2) t^{2}-\theta\left(P_{o}+e P_{o}-e c\right) t+e\left(P_{o}-c\right)^{2} / 2 .
\end{aligned}
$$

Note that $f(0)=e\left(P_{o}-c\right)^{2} / 2>0$ and $f\left(P_{o}-c\right)=-\theta\left(P_{o}-c\right) P_{o}<0$, i.e., the entry of an equally 
efficient firm always leads to a welfare increase, while entry by a firm with a large cost disadvantage equal to the difference between pre-entry price and marginal cost always leads to a welfare decrease. In general, entry results in a welfare increase $\Delta \mathrm{W}>0$ when the entrant's cost disadvantage is not too high, $\mathrm{t}<\mathrm{t}^{*}$, where ${ }^{27}$

$$
t^{*}=\left\{\theta\left(P_{o}+e P_{o}-e c\right)-\left[\left(P_{o}-c\right)^{2} e^{2}(1-\theta)^{2}+\theta^{2} P_{o}\left(2 e\left(P_{o}-c\right)+P_{o}\right)\right]^{1 / 2}\right\} /[e(2 \theta-1)]
$$

$27 \mathrm{f}(\mathrm{t})$ can be written as

$$
f(t)=\alpha t^{2}+\beta t+\gamma
$$

where

$$
\alpha=\mathrm{e}(\theta-1 / 2), \quad \beta=-\theta\left(\mathrm{P}_{\mathrm{o}}+\mathrm{eP}_{\mathrm{o}}-\mathrm{ec}\right)<0, \quad \gamma=\mathrm{e}\left(\mathrm{P}_{\mathrm{o}}-\mathrm{c}\right)^{2} / 2>0
$$

For $\alpha \neq 0$, the roots of $\mathrm{f}(\mathrm{t})$ can be written as

$$
t_{1,2}=\left[-\beta \pm\left(\beta^{2}-4 \alpha \gamma\right)^{1 / 2}\right] /(2 \alpha)
$$

where

$$
\begin{gathered}
\beta^{2}-4 \alpha \gamma=\theta^{2}\left(P_{o}+e P_{o}-e c\right)^{2}-4(\theta-1 / 2) e^{2}\left(P_{o}-c\right)^{2} / 2 \\
=e^{2}\left(P_{o}-c\right)^{2}(1-\theta)^{2}+\theta^{2} P_{o}\left[2 e\left(P_{o}-c\right)+P_{o}\right] .
\end{gathered}
$$

The relevant root is the only positive one,

$$
\begin{gathered}
\mathrm{t}^{*}=\mathrm{t}_{2}=\left[-\beta-\left(\beta^{2}-4 \alpha \gamma\right)^{1 / 2}\right] /(2 \alpha) \\
=\left\{\theta\left(\mathrm{P}_{\mathrm{o}}+\mathrm{e} \mathrm{P}_{\mathrm{o}}-\mathrm{ec}\right)-\left[\left(\mathrm{P}_{\mathrm{o}}-\mathrm{c}\right)^{2} \mathrm{e}^{2}(1-\theta)^{2}+\theta^{2} \mathrm{P}_{\mathrm{o}}\left(2 \mathrm{e}\left(\mathrm{P}_{\mathrm{o}}-\mathrm{c}\right)+\mathrm{P}_{\mathrm{o}}\right)\right]^{1 / 2}\right\} /[\mathrm{e}(2 \theta-1)] .
\end{gathered}
$$

For $\theta=1 / 2$ (implying $\alpha=0$ ), $\mathrm{f}(\mathrm{t})=\beta \mathrm{t}+\gamma$, and therefore

$$
\mathrm{f}(\mathrm{t})>0 \Leftrightarrow \mathrm{t}<\mathrm{t}^{*}=-\gamma / \beta=\mathrm{e}\left(\mathrm{P}_{\mathrm{o}}-\mathrm{c}\right)^{2} /\left[2 \theta\left(\mathrm{P}_{\mathrm{o}}+\mathrm{eP} \mathrm{P}_{\mathrm{o}}-\mathrm{ec}\right)\right] .
$$


for $\theta \neq 1 / 2$, and ${ }^{28}$

$$
\mathrm{t}^{*}=\mathrm{e}\left(\mathrm{P}_{\mathrm{o}}-\mathrm{c}\right)^{2} /\left[2 \theta\left(\mathrm{P}_{\mathrm{o}}+\mathrm{eP}-\mathrm{ec}\right)\right] \text { for } \theta=1 / 2
$$

${ }^{28}$ It is easy to show that $t^{*}$ decreases continuously with $\theta$. 